\title{
Re-Ajustando la Teorética de los Museos (y por ende, sus Prácticas) para Incluir las Necesidades y Valores de la Comunidad indígena
}

Re-Adjusting Museum Theoretics (and Hence, Practices) to Include Indigenous Community Needs and Values

Jessie Ryker-Crawford

\section{OpenEdition Journals}

\section{Edición electrónica}

URL: https://journals.openedition.org/iss/3442

DOI: 10.4000/iss.3442

ISSN: 2306-4161

Editor

ICOM - International Council of Museums

Edición impresa

Fecha de publicación: 18 diciembre 2021

Paginación: 142-149

ISBN: 978-92-9012-446-7

ISSN: 2309-1290

Referencia electrónica

Jessie Ryker-Crawford, «Re-Ajustando la Teorética de los Museos (y por ende, sus Prácticas) para Incluir las Necesidades y Valores de la Comunidad indígena», ICOFOM Study Series [En línea], 49-7 I 2021, Publicado el 18 diciembre 2021, consultado el 08 enero 2022. URL: http:// journals.openedition.org/iss/3442 ; DOl: https://doi.org/10.4000/iss.3442 


\section{Re-Ajustando la Teorética ${ }^{1}$ \\ de los Museos \\ (y por ende, \\ sus Prácticas) \\ para Incluir las \\ Necesidades \\ y Valores de \\ la Comunidad \\ indígena.}

Jessie Ryker-Crawford

Institute of American Indian Arts - Santa Fe, USA

I. La teoría (el acto integral de aplicar tanto la teoría como la hipótesis) afecta en última instancia los hallazgos del investigador sobre cualquier tema dado. [All footnote citations in Spanish are applied from Google translation from English to Spanish. Todas las citas de notas a pie de página en español se aplican a partir de la traducción de Google del inglés al español.] 
INTRODUCCIÓN:

Boozhoo. Primero me gustaría presentarme, en mi idioma si se me permite.

Niin Jessie Ryker-Crawford ndizhinikaaz. Ninisa Anishinaabe, miinawah Gaa-waabaabiganikaag ishkonigan nindonjiibaa; Maang niindoodem.

Saludos. Mi nombre es Jessie Ryker-Crawford. Soy Chippewa (o Anishinaabe), y soy de la Nación Chippewa de White Earth (Tierra Blanca);

Pertenezco al Clan Loon. ${ }^{2}$

\section{Reconocimiento de Tierras}

Me gustaría reconocer a los pueblos indígenas de Nueva Hampshire: las Naciones Abenaki, Maleseet, Micmac, Passamaquoddy, Penobscot, y Pennacook. Y aquellos que tradicionalmente incluyeron las tierras de New Hampshire como una región de caza y eco-agrícola: las Naciones Akwesasne, Kahnawake, Mahican, Nipmuck, Pequot, Schaghticoke, y Wampanoag.

Si en mi reconocimiento he pasado por alto alguna Nación tribal, les ruego me perdonen.

Si no están acostumbrados a las presentaciones y reconocimientos de los Nativos Americanos, el comienzo de mi presentación les puede parecer un poco largo. Pero hay una razón por la que nos tomamos el tiempo para reconocer y honrar a quienes nos han traído al lugar donde nos encontramos ahora. Es una manera de ser humildes y recordar que ninguno de nosotros está sólo en este espacio que llamamos "ahora." Las presentaciones y los reconocimientos nos aterrizan en el hecho de que todo lo que hacemos es una actividad colaborativa - y es bueno reconocer a quienes podamos, cuando podamos.

\section{Reajustar la Teoría de los Museos}

Aquellos de nosotros en el campo de los museos debemos a otros nuestro sustento y la riqueza de nuestras profesiones: a los anteriores profesionales de los museos y a los pueblos de nuestras y de otras culturas. Somos mucho más que simples administradores de los objetos inanimados que se encuentran dentro de nuestras colecciones. También somos servidores de las culturas y comunidades de las que obtenemos conocimiento, entendimiento profundo, e iluminación, tanto personal como profesional. Porque estamos aquí para ayudar a compartir las historias que durante tantos años han sido silenciadas, mal comunicadas, desfiguradas y mal comprendidas.

2. La Dra. Jessie Ryker-Crawford es Presidenta del Departamento de Estudios de Museos y Profesora de Estudios de Museos en el Instituto de Artes Indígenas Americanas en Santa Fe, Nuevo México, EE. UU. Su trabajo se ha centrado en la indigenización y descolonización del ámbito museístico. 
Porque como todos sabemos, es un hecho que podemos abrir cualquier publicación sobre el patrimonio material e inmaterial de otros pueblos, y encontrar una mirada con descripciones inexactas y despectivas. O peor aún, la exposición de conocimiento Ceremonial sagrado que, debido a que ahora está impreso, se presenta alejado del contexto de los sistemas de conocimiento de los que emerge.

Sabemos que, desafortunadamente, es un hecho que podemos entrar en los sistemas de almacenamiento de nuestras instituciones y encontrar objetos-antepasados que nunca debieron encontrarse allí, y salas de exhibición que presentan una cultura material que nunca estuvo destinada a ser puesta a la vista.

Estas realidades tienen mucho que ver con teorías y, por tanto, prácticas antropológicas, arqueológicos y museológicas que han permanecido en vigor desde hace ya cientos de años. Porque las teorías llevan a la práctica. Y teorías integras, sanas, inclusivas y benéficas conducen a prácticas íntegras, sanas, inclusivas y benéficas.

Sin embargo, nuevas conversaciones a partir de la crítica sí están emergiendo en forma transversal a nuestras disciplinas, y las de otros.

No podemos negar que el campo de la museología se originó a partir de teorías y prácticas coloniales; teorías que han estado sesgadas, basadas en presunciones de que algunas culturas están "más alto en la escala evolutiva," mientras que otras son "menos que." En las palabras de uno de mis estudiantes y colega en el campo de los museos, Alison Guzmán, "aquí estamos hoy, siglos después, reajustando el modelo de museo para abordar las necesidades y valores de las comunidades indígenas, para de poder representarnos a nosotros mismos ... y administrar [nuestro] propio patrimonio cultural" (la discusión de clase, 16 de abril de 2020).

Arthur Amiotte, un Oglala Lakota artista y educador, habló del arte Nativo Americano; pero sus palabras resuenan al referirse a todos los objetos de valor cultural. Él afirma que:

El Indio Americano se ha aferrado tenazmente a [sus] artes, no en el sentido únicamente objetual, sino más bien en tanto tejido que amarra y sostiene unidas muchas dimensiones de [nuestra] propia existencia. Las artes son para [nosotros] una expresión de las fuerzas integradas que anudan y unifican todos los aspectos de la vida ...(El artista Nativo Americano) es, por lo tanto, los ojos, oídos y voz de [su] propia época. Más aún, [ellos son un] registro personal que...es el depósito parcial o la enciclopedia de [nuestras] tradición[es] oral[es]. (Amiotte, 1977, como se cita en Hill, 1992, p. 10). 
Como pueblos Nativos Americanos, nos encontramos de-construyendo identidades coloniales mientras que negociamos el yo cultural en el mundo actual. Estamos intentando...no, emprendiendo activamente, nuevas formas de presentar la identidad y continuidad cultural, como son expresadas a través de las instituciones de los museos - recopilando, sosteniendo y exhibiendo nuestra cultura a través de presentaciones y discusiones sobre nuestro patrimonio cultural tangible e intangible.

Cuestiones sociales, históricas y políticas aún esperan ser articuladas y analizadas, incorporando la antropología crítica y los enfoques teóricos, al discurso visual y las políticas de la representación a través de nuestros objetos.

En un intento por formular nuevas formas de pensar sobre los temas que conciernen a los pueblos indígenas de América del Norte, se requiere utilizar y abrazar enfoques etnográficos compartidos y métodos de investigación inclusivos.

\section{Estudio de Caso de Una Curaduría Colaborativa: Árboles de Durazno}

Me gustaría detenerme aquí y contar una historia de árboles de durazno.

A mis estudiantes de museología que están escuchando, les pido disculpas. Porque han escuchado esto ya varias veces...

Una comunidad tribal se acercó a nosotros, en el Programa de Estudios de Museos del Instituto de Arte Indígena Americana ${ }^{3}$ con el deseo de crear una serie de mini-exhibiciones sobre su comunidad.

Siguiendo, como lo hacemos, los métodos de curaduría colaborativa, ${ }^{4}$ tanto los profesores como los estudiantes trabajaron con líderes tribales para organizar una reunión comunitaria a fin de discutir posibles temas de exhibición.

Un anuncio fue enviado a la comunidad, y les preguntamos a los miembros de la tribu quienes, en su comunidad, podrían ser contratados para preparar una merienda que incluyera comidas tradicionales, de modo que primero pudiéramos sentarnos y comer juntos. Esta es una metodología para reunirse, importante, tradicional.

3. El Instituto de Artes Indígenas Americanas (IAIA) es una universidad multi-tribal de nativos americanos con sede en Santa Fe, Nuevo México. Iniciada en 1962 y acreditada por la Comisión de Educación Superior de los Estados Unidos en 1973, la IAIA ofrece programas de grado indígenas en estudio de las artes, escritura creativa, estudios liberales indígenas, artes cinematográficas, artes escénicas y estudios de museos. Su programa de estudios de museos es el programa de grado en museos más antiguo de la nación. Aunque se centra en ofrecer planes de estudio para estudiantes nativos americanos que son específicos del pensamiento y las filosofías indígenas, la IAIA está abierta a todos los estudiantes de todo el mundo.

4. Para obtener más información sobre las teorías que pertenecen a la curaduría colaborativa, consulte Lonetree (2012), Tuhiwai Smith (1999) y Wilson (2008) en la bibliografía. 
El Museo de Historia de Nuevo México y el Museo Maxwell de Antropología habían dado a la tribu acceso completo a sus colecciones de archivos de imágenes - más de 300 imágenes de alta resolución. Preparamos una presentación de diapositivas, con la esperanza de que las imágenes ayudaran a estimular ideas para la exposición.

El encuentro incluyó a jóvenes y ancianos, miembros del consejo y cultores del idioma. Comenzamos describiendo los pasos que seguimos al construir una exhibición, desde el intercambio de ideas, a conducir más investigación, a elegir objetos o imágenes, a producir el texto de la exhibición. Mostramos algunos ejemplos y luego comenzamos la presentación de diapositivas. La presentación de diapositivas era imperativa. Poco a poco, fueron surgiendo discusiones entre los miembros de la comunidad, con solicitudes para volver a ciertas imágenes y para pausar las diapositivas en otras. Las discusiones pasaron al lenguaje tribal y nosotros respetuosamente permanecimos en silencio mientras las discusiones se llevaban a cabo.

Estábamos muy conscientes de que cuando las discusiones volvieran al inglés, sería para incluirnos a nosotros, profesores y estudiantes de otras tribus. La información que surgió de esas discusiones fue invaluable.

En primer lugar, varias de las diapositivas estaban al revés. Habiendo sido hechas en placas de vidrio-muchas de los 1800s-el fotógrafo había escrito en la parte posterior de la diapositiva, lejos de la emulsión. De esta manera, se mostraba a los bailarines sosteniendo objetos en la mano equivocada, y las kivas ceremoniales se mostraban al revés.

Lo segundo que surgió fue una profunda discusión sobre los árboles de durazno que alguna vez rodearon la plaza comunitaria. Los ancianos rememoraron estos árboles, que habían desaparecido hace mucho tiempo, y entre los jóvenes y los ancianos comenzó una discusión sobre por qué ya no existían. Se llegó a un consenso de que habían desaparecido durante la década de 1930, cuando las fuerzas gubernamentales de vivienda dictaron que las casas construidas para los miembros de la tribu se levantaran lejos de la plaza comunal y las estructuras tradicionales de adobe, colocadas en cambio en las tierras asignadas forzosamente a cada familia.

Los ancianos insistieron en que, en algún momento, se produjera una exhibición grande y permanente sobre la importancia de esos árboles de durazno para la comunidad.

\section{Lo Que Aprendimos del Proceso Colaborativo}

Esta historia destaca muchas cosas, como suelen hacer las historias. Nos ayuda a darnos cuenta, y nos abren posibilidades, de espacios curatoriales que no podrían haber sido ideados por quienes están afuera de las propias comunidades; más investigación sobre los proyectos de vivienda del Departamento de Vivienda y Desarrollo Urbano de EE.UU. de la era de 1930, y su impacto 
en las formas de vida tradicionales; de la migración de gente de España hacia el suroeste en la era de los 1600, y tanto las historias de colonización forzada como de la resiliencia de los pueblos Nativos y la integración de importantes cultivos alimentarios y árboles frutales. De tiempos de cambio que recuerdan los mayores de una comunidad.

También destaca que nosotros, como curadores, administradores de colecciones y profesionales de museos, tenemos una plétora de historias que podemos ayudar a compartir, siempre que entendamos que todavía nos aferramos a teorías y metodologías de "hacer museología" de décadas atrás, a las que inconscientemente podemos estar todavía aferrándonos.

Esta historia destaca lo que puede surgir cuando las metodologías de investigación y la teoría curatorial están profundamente arraigadas a una ética de métodos de colaboración cuidadosos y conscientes. Que a través de estos métodos éticos, lo que aún está por explorarse es cuán multifacética la cultura Nativo Americana es, con discursos internos que están esperando para ser compartido con las comunidades externas y otras culturas, así como internamente, que pueden resonar y sumar a nuestra celebración general de la humanidad.

Digo multifacético, porque éstas historias del "yo" reflejan trasfondos históricos, políticos y filosóficos nativos, comparables y a la vez opuestos. La negociación de la identidad Nativo Americana opera en muchos niveles diferentes e incluye diversas perspectivas y voces discursivas nativas.

Lo que queda por ser presentado en los museos y las historias que estos ayudan a compartir es un abordaje etnográfico de la curaduría en tanto discurso indígena sobre la propia identidad nativa, que refleja una maniobra interna y, a menudo, una respuesta dialéctica a las presiones coloniales, tanto históricas como contemporáneas.

No olvidemos incluir obras de arte contemporáneas Nativo Americanas, que a menudo abordan cuestiones culturales, sociales y políticas que son de relevancia y preocupación para las comunidades nativas de hoy, que ilustran una representación inter-cultural de una identidad cultural Nativo Americana.

Porque nuestro arte es un discurso visual que refleja, no una presentación homogénea de la identidad nativa, sino que más bien, habla de historias y experiencias culturales únicas. Y rechaza las etiquetas estereotípicas generadas fuera de las comunidades Nativas Americanas.

Porque esos estereotipos a menudo fuerzan a los individuos nativos a alinearse política e ideológicamente con categorías arbitrarias de una identidad nativa tradicional versus una moderna - un hecho del que muchos artistas nativos contemporáneos son dolorosamente conscientes. Esta crisis de representación subyacente está entretejida en y a través del arte nativo americano contemporáneo de varias maneras, exponiendo un discurso interno que a veces es fragmentario y controvertido, aunque rico en diálogo. Lo cual es lo que nos interesa, en este campo educativo nuestro. 
A través de las formas en que realizamos nuestras prácticas museológicas; nuestro coleccionar, nuestro exhibir y nuestra presentación de las culturas Nativas Americanas, podemos ayudar a responder las preguntas con las que nosotros, como pueblos Nativos Americanos, estamos batallando: “¿Qué rol juega la tradición dentro de una identidad nativa moderna?" ¿Cómo en la actualidad la identidad cultural se está negociando y redefiniendo?" "Qué experiencias han compartido los diversos pueblos Nativo Americanos durante el período posterior al contacto?" ¿Qué podemos decir sobre una experiencia histórica colectiva, así como sobre nuestras experiencias culturales distintivas?"

Son éstas preguntas las que con mayor frecuencia se exploran internamente (y en diversos grados) dentro de nuestras comunidades. Se hacen eco de un discurso que ha estado en vigor desde el contacto inicial y conquista por los europeos, y abarcan los temas mucho más amplios de las crisis sociales-asimilación, pérdida/retención de la cultura, relaciones de poder, redefinición del yo-todo ello enmarcado en contextos y movimientos históricos específicos.

Teoremas (y por tanto, prácticas) con décadas de antigüedad, han funcionado para silenciar historias que requieren ser contadas. Seguimos esas teorías sesgadas sin tener la intención de hacerlo. Porque son la forma en que siempre se han hecho las cosas.

Entrar en una comunidad, y lentamente hacer lazos fuertes, y escuchar con atención, sin dictar cuánto tiempo puede tomar o en qué dirección puede ir, puede ser incómodo. Porque no se nos enseñan métodos que funcionan. Pero éstos existen (Abu-Saad \& Champagne, 2006; Bench, 2014; Chilisa, 2012; LaDuke, 2005; Lambert, 2014; Lischke \& McNab, 2005; Lonetree, 2012; Peers \& Brown, 2003; Tuhiwai Smith, 1999; Wilson, 2008).

Modelos colaborativos de investigación. Métodos y prácticas curatoriales indígenas. Metodologías de investigación indígenas. Estas son herramientas que están siendo difundidas por los propios profesionales indígenas y poseedores de conocimientos. Reflejan un cambio en el juego de poder, y todas ponen la experticia en manos de las propias comunidades en lugar de en manos del investigador, el coleccionista, el profesional del museo. Como debería ser.

Tomemos en serio nuestra responsabilidad como custodios y servidores de los demás. Rompamos con la teoría de que nosotros somos los expertos. Vamos abriendo las posibilidades de ayudar a contar historias que esperan ser contadas, que no pueden de ninguna manera originarse de nosotros. De esta manera, nuestros cofres con colecciones de objetos y nuestras exhibiciones pueden reflejar las necesidades, deseos y valores de las comunidades de origen, de las que mantenemos éstos, actuando como sus custodios culturales - para quienquiera que esa comunidad sea: tribal, étnica, sub-representada, o convencional.

Miigwetch. 


\section{References}

Abu-Saad, I., \& Champagne, D. (Eds.). (2006). Indigenous education and empowerment: International perspectives. AltaMira.

Bench, R. (2014). Interpreting Native American history and culture at museums and historic sites. Roman \& Littlefield.

Chilisa, B. (2012). Indigenous research methodologies. Sage.

Hill, R. (Ed.). (1992). Creativity is our tradition: Three decades of contemporary Indian art at the Institute of American Indian Arts. Institute of American Indian and Alaska Native Culture and Arts Development.

LaDuke, W. (2005). Recovering the sacred: The power of naming and claiming. South End Press.

Lambert, L. (2014). Research for Indigenous survival. University of Nebraska Press.

Lischke, U., \& McNab, D.T. (Eds.). (2005). Walking a tightrope: Aboriginal people and their representation. Wilfrid Laurier University Press.

Lonetree, Amy. (2012). Decolonizing museums: Representing Native America in national and tribal museums. The University of North Carolina Press.

Peers, L., \& Brown, A. K. (2003). Museums and source communities: A Routledge reader. Routledge.

Tuhiwai Smith, L. (1999). Decolonizing methodologies: Research and Indigenous peoples. Zed Books, Ltd.

Wilson, S. (2008). Research is ceremony: Indigenous research methods. Fernwood Publishing. 